\title{
Self-medication Practice in Primary Dysmenorrhea among Nursing Students: A Cross Sectional Study
}

\author{
Lokeshwar Chaurasia ${ }^{1 *}$, Laxmi Shah ${ }^{2}$, Gita Paudel ${ }^{3}$, Deependra Prasad Sarraf ${ }^{4}$, Poonam Shah $^{2}$, \\ Jitendra Kumar Singh ${ }^{5}$
}

\begin{abstract}
${ }^{1}$ Department of Pharmacology, Janaki Medical College, Tribhuvan University, Janakpur, Nepal
${ }^{2}$ College of Nursing, Sinha Health Foundation, Purbanchal University, Janakpur, Nepal

${ }^{3}$ Department of Pharmacology, Chitwan Medical College, Tribhuvan University, Chitwan, Nepal

${ }^{4}$ Department of Pharmacology, B.P Koirala Institute of Health Sciences, Dharan, Nepal

${ }^{5}$ Department of Community Medicine, Janaki Medical College, Tribhuvan University, Janakpur, Nepal
\end{abstract}

\section{ARTICLE INFO}

Article history:

Received: 17 March 2021

Revised: 27 April 2021

Accepted: 19 June 2021

*Correspondence:

Dr. Lokeshwar Chaurasia

Janaki Medical College,

Tribhuvan University, Janakpur, Nepal

E-mail:

dr.lokc34@gmail.com

ORCID ID:

0000-0001-6561-4642

Citation:

Chaurasia L, Shah L, Paudel G, Shraff DP, Shah P, Singh JK. Self-medication Practice in Primary Dysmenorrhea among Nursing Students: A Cross Sectional Study. MedS. J. Med. Sci. 2021; 1(1):67-75

\begin{abstract}
ABSTARCT
INTRODUCTION: Self-medication and home remedies are most commonly employed for relief from menstrual discomfort in female students. Self-medication practice varies among adolescent female students. Hence, this study aims to observe and analyze self-medication practice and drugs used for primary dysmenorrhea among nursing students. MATERIALS AND METHODS: This cross sectional study was conducted at Janaki Medical College and College of Nursing, Sinha Health Foundation, Dhanusha from October 2019 to December 2019, among nursing students of various academic years of intermediate level and bachelor level through structured questionnaire. Data analysis was carried out using SPSS version 21.0. RESULTS: Out of 156 female students, the mean age of menarche was $13.20 \pm 1.53$, interval of menstrual cycle was $30.29 \pm 7.26$. Majority $(82.1 \%)$ of the female students reported lower abdominal pain during menstrual bleeding, of which $48.4 \%$ had pain for less than 1 day, $47.7 \%$ had pain for $1-3$ days and $3.9 \%$ had pain for more than 3 days. Self-medication practice was observed in $35.20 \%$ of students while $60.20 \%$ of them practiced resting in bed for pain relief during menstrual bleeding. The most commonly self-medicated drug was mefenamic acid $(64.4 \%)$, followed by paracetamol (40\%), ibuprofen $(26.7 \%)$ and nimesulide (13.3\%). CONCLUSIONS: Self-medication of drugs was found to be lower in primary dysmenorrhea among nursing students. Therefore, education programs on the drawbacks of self-medication of drugs needs to be implemented; properly and timely.
\end{abstract}

Key words: Self-medication, primary dysmenorrhea, nursing students.

\section{INTRODUCTION}

According to the WHO's definition, self-medication $(\mathrm{SM})$ is the use of drugs to treat self-diagnosed disorders or symptom's or the intermittent or continued use of a prescribed drug for chronic or recurrent diseases or symptoms [1]. It involves the process of getting and consuming drugs without the advice of a physician either for diagnosis, treatment, prescription, surveillance or monitoring [2]. $\mathrm{SM}$ is a fairly common practice, for minor health problems, it often provides cheap, rapid, and convenient solutions, outside of the health care system of many countries. Potential risks include incorrect self-diagnosis, improper dosage, inappropriate choice of therapy, masking of severe disease and drug interactions. Little is known about the SM of dysmenorrhea by adolescent girls. Some girls discuss dysmenorrhea with family and friends and the majority may not seek medical advice. As dysmenorrhea is a common problem for adolescents, it is essential that these girls be aware of the normal and abnormal symptoms of menstruation [3]. Factors influencing frequency of $\mathrm{SM}$ in the previous studies are age, educational level, family attitudes, advertising of drug manufacturers, legislation regulating dispensing and sale of drugs, previous experiences with the symptoms or disease, significance attributed to the disease $[4,5]$ home-kept prescription drugs [6] and 
economic situation of respondents [1,4]. Primary dysmenorrhea is defined as cramping pain in the lower abdomen occurring just before or during menstruation, in the absence of other diseases such as endometriosis. Increased production of endometrial prostaglandin, underlies the pathogenesis of PD leading to increased uterine tone and stronger, more frequent uterine contractions [7]. All these symptoms occur just before or during the menses in women with normal pelvic anatomy. The prevalence is particularly high among adolescents (50-70\%) disrupting educational and social life, leading to school absenteeism and loss of labor [8]. The problem is often under diagnosed and under treated. Several studies have

\section{MATERIALS AND METHODS}

\section{Study design and setting}

This cross sectional study was conducted at College of Nursing, Janaki Medical College and College of Nursing, Sinha Health Foundation, Dhanusha from October 2019 to December 2019. Students of various academic years of intermediate level and bachelor level nursing program were include in this study.

Participants and study procedures Female nursing students were briefed in detail about the objective and methods of the study and a structured questionnaire comprising of demographic details and self-medication practice for primary dysmenorrhea was provided to the students. The questionnaire for data collection was distributed to students in classrooms in the first period and was collected after the last period on the same day. It consisted of socio-demographic section followed by

\section{RESULTS}

\section{Sociodemographic characteristics}

In the current study, out of 156 female students, the mean age of female students was $18.92 \pm$ 2.52.Percentage of students unmarried was 82.7 while married was 17.3. Majority of the students belonged to intermediate level (65.4\%) compared to bachelor level (34.6\%). Also, majority students were residents of province 2 (Table 1 ). The mean age menarche was $13.20 \pm 1.53$ years, mean interval of menstrual cycle was $30.29 \pm 7.26$ and the duration of reported that SM starts with the onset of adolescence and increases with age $[9,10,11]$. Therefore, the issue of SM among adolescents represents an emerging topic in scientific research [9]. In developing countries, the easy availability of a wide range of drugs and inadequate health services increased the prevalence of SM [12]. Inappropriate self-medication practice (SMP) results in economic wastes, damage of vital organs, incorrect therapy selection, risk of adverse drug reactions and development of antimicrobialresistant pathogens.therefore this study was conducted in nursing adolescent students to observe and analyse SMP and drugs used for primary dysmenorrhea among nursing students.

questions related to menarche, severity of lower abdominal pain during menstrual bleeding and the methods adapted for relief of pain during menstrual bleeding. The Institutional Review Committee (IRC) of Janaki Medical College, Tribhuvan University reviewed and approved the study.

Statistical consideration The data was entered into MS excel and transferred to SPSS version 21.0 for analysis. Descriptive statistics were employed to summarize the data. $\mathrm{p}<0.05$ was considered statistically significant. Variables associated with $\mathrm{SM}$, were entered into the multivariate logistic regression analysis, which was used to compute adjusted odds ratio (OR) and 95\% confidence intervals $(95 \% \mathrm{CI})$ to assess the independent associations of these variables with self-medication.

menstrual bleeding was $4.84 \pm 1.15$. Most of them had a regular pattern $(77.6 \%)$ of menstrual bleeding while $82.1 \%$ of the female students reported lower abdominal pain during menstrual bleeding, of which $48.4 \%$ had pain for less than 1 day, $47.7 \%$ had pain for $1-3$ days and $3.9 \%$ had pain for more than 3 days. $28.1 \%$ of the respondents had severe, $33.6 \%$ had moderate and $38.3 \%$ had mild lower abdominal pain (Table 2 and 3 ). 


\begin{tabular}{|c|c|c|}
\hline Characteristics & Number & Percentage (\%) \\
\hline Age $[$ Mean \pm SD] & $18.92 \pm 2.52$ & - \\
\hline \multicolumn{3}{|l|}{ Caste/Ethnicity } \\
\hline $\begin{array}{l}\text { Upper Caste } \\
\text { Group }\end{array}$ & 123 & 78.9 \\
\hline Adibasi/Janajati & 28 & 17.9 \\
\hline Dalit & 5 & 3.2 \\
\hline \multicolumn{3}{|l|}{ Marital Status } \\
\hline Married & 27 & 17.3 \\
\hline Unmarried & 129 & 82.7 \\
\hline \multicolumn{3}{|l|}{ Academic Level } \\
\hline Intermediate & 102 & 65.4 \\
\hline Bachelor & 54 & 34.6 \\
\hline \multicolumn{3}{|l|}{ Academic year } \\
\hline $1^{\text {st }}$ year & 49 & 31.4 \\
\hline $2^{\text {nd }}$ year & 48 & 30.8 \\
\hline $3^{\text {rd }}$ year & 46 & 29.5 \\
\hline $4^{\text {th }}$ year & 13 & 8.3 \\
\hline \multicolumn{3}{|l|}{ Province } \\
\hline Province-1 & 26 & 16.7 \\
\hline Province-2 & 95 & 60.9 \\
\hline Province-3 & 17 & 10.9 \\
\hline Province-4 & 4 & 2.6 \\
\hline Province-5 & 3 & 1.9 \\
\hline Province-6 & 9 & 5.8 \\
\hline Province-7 & 2 & 1.3 \\
\hline Total & 156 & 100.0 \\
\hline
\end{tabular}

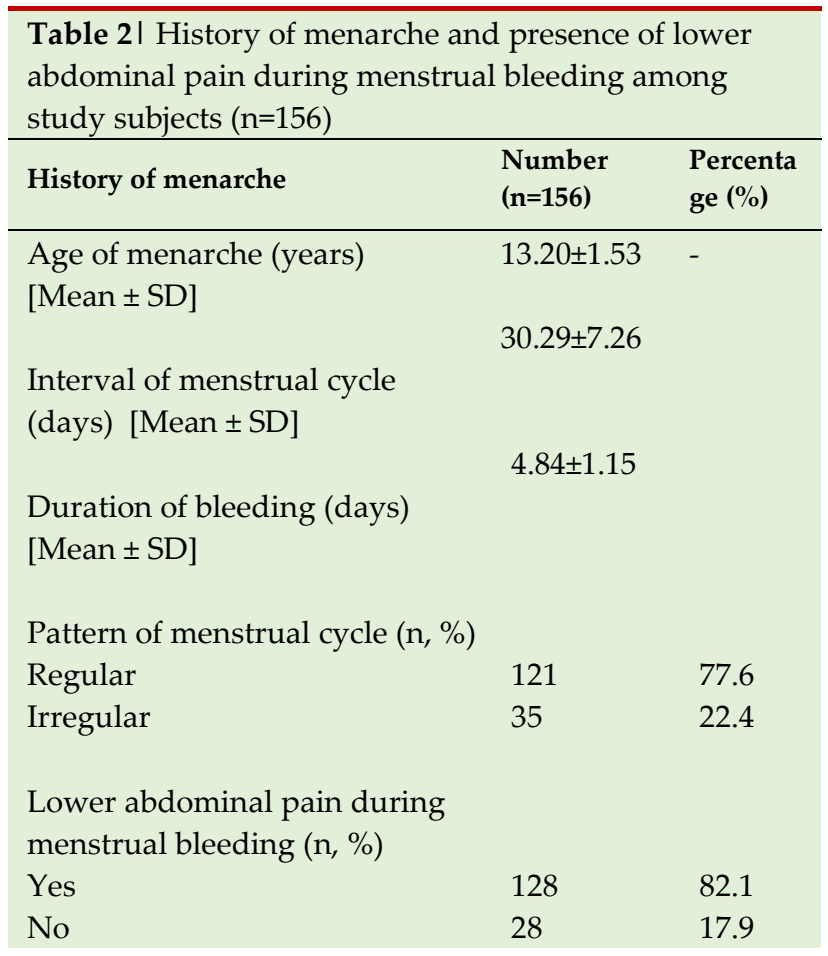

Factor associated with self-medication practice during pain in menstrual bleeding among study subjects

SMP was found to be higher in students aged $>20$ years $(45 \%)$, in upper caste group (39.2\%), in married students(61.1\%) and in bachelor level students (37.5\%), as shown in Table 4 .

Out of 45 students, practicing selfmedication, it was found that those students with age at menarche $\leq 13$ years $(37.9 \%)$, with 28 days menstrual cycle interval (39.6\%), with more than 4 days of bleeding duration $(36.8 \%)$ and with irregular menstrual bleeding (41.9\%) were associated with higher pattern of SM. Similarly, SMP was associated with history of abdominal pain before or after start of menarche $(36.9 \%)$, with abdominal pain starting before and after one day of start of menstrual bleeding $(40 \%)$, with pain for $\geq 1$ day $(39.1 \%)$ and with severe pain during menstrual bleeding $(61.1 \%)$, as shown in Table 5 .

Based on multivariable analysis, selfmedication practice was associated more with married students (3.51) and with severe lower abdominal pain during menstrual bleeding (4.82), as shown in Table 6. 


\begin{tabular}{lcc}
\hline \multicolumn{3}{l}{ Table 3 I History of lower abdominal pain during menstrual bleeding among study subjects ( $\mathbf{n}=128)$} \\
\hline History of lower abdominal pain & Number (n=128) & Percentage (\%) \\
Abdominal pain started & 39 & 30.4 \\
Before start of menarche & 63 & 49.2 \\
With start of menarche & 26 & 20.4 \\
After start of menarche & & \\
Pain started before menstrual bleeding & 24 & 18.8 \\
Less than 1 year & 29 & 22.7 \\
1-3 years & 14 & 10.9 \\
More than 3 years & 61 & 47.7 \\
Don't remember & & \\
Pain started at the time of menstrual bleeding & 47 & 36.7 \\
One or more day before start of menstrual bleeding & 71 & 55.5 \\
On the same day on start of menstrual bleeding & 10 & 7.8 \\
One or more days after start of menstrual bleeding & & \\
Duration of pain during menstrual bleeding & 62 & 48.4 \\
Less than 1 days & 61 & 47.7 \\
1-3 days & 5 & 3.9 \\
More than 3 days & & \\
Family history of pain among during menstrual bleeding & 29 & 22.6 \\
Mother & 20 & 15.6 \\
Sister & 16 & 12.5 \\
Mother \& Sister & 63 & 49.3 \\
None & & \\
Severity of pain (Score) & 49 & 38.3 \\
Mild & 43 & 33.6 \\
Moderate & 36 & 28.1 \\
Severe & & \\
& & \\
& &
\end{tabular}

\begin{tabular}{|c|c|c|c|c|}
\hline \multirow{3}{*}{$\begin{array}{l}\text { Table } 4 \mid \text { Associatio } \\
\text { characteristics of stud }\end{array}$} & \multirow{2}{*}{\multicolumn{2}{|c|}{$\begin{array}{l}\text { n practice during pain in menstrual bl } \\
\text { Self-medication practice } \\
\text { Yes, } \mathrm{n}=45,(\%) \quad \text { No, } \mathrm{n}=83,(\%)\end{array}$}} & \multirow{2}{*}{$\begin{array}{l}\text { ing and socio-d } \\
\mathrm{OR}(95 \% \mathrm{CI})\end{array}$} & \multirow{2}{*}{$\begin{array}{l}\text { mographi } \\
\text { p-value }\end{array}$} \\
\hline & & & & \\
\hline & \multicolumn{4}{|c|}{ Current Age } \\
\hline More than 20 years & $18(45.0)$ & $22(55.0)$ & $1.84(0.85-3.99)$ & 0.116 \\
\hline 20 years \& less & $27(30.7)$ & $61(69.3)$ & 1.00 & \\
\hline \multicolumn{5}{|l|}{ Caste/Ethnicity } \\
\hline Upper Caste Group & $40(39.2)$ & $62(60.8)$ & $2.71(0.94-7.76)$ & 0.057 \\
\hline Others & $5(19.2)$ & $21(80.8)$ & & \\
\hline \multicolumn{5}{|l|}{ Marital Status } \\
\hline Married & $11(61.1)$ & $7(39.9)$ & $3.51(1.25-9.84)$ & 0.013 \\
\hline Unmarried & $34(30.9)$ & $76(69.1)$ & 1.00 & \\
\hline \multicolumn{5}{|l|}{ Academic Level } \\
\hline Intermediate & $30(34.1)$ & $58(65.9)$ & $0.86(0.39-1.87)$ & 0.708 \\
\hline Bachelor & $15(37.5)$ & $25(62.5)$ & 1.00 & \\
\hline \multicolumn{5}{|l|}{ Academic year } \\
\hline $1^{\text {st }}$ year & $16(43.2)$ & $21(56.8)$ & $1.27(0.26-6.11)$ & \\
\hline $2^{\text {nd }}$ year & $11(25.6)$ & $32(74.4)$ & $0.57(0.11-2.80)$ & 0.406 \\
\hline $3^{\text {rd }}$ year & $15(37.5)$ & $25(62.5)$ & $1.01(0.20-4.79)$ & \\
\hline $4^{\text {th }}$ year & $3(37.5)$ & $5(62.5)$ & 1.00 & \\
\hline
\end{tabular}




\begin{tabular}{|c|c|c|c|c|}
\hline & Self-medi & n practice & & \\
\hline & $\begin{array}{l}\text { Yes, } \\
n=45,(\%)\end{array}$ & $\begin{array}{l}\text { No, } \\
n=83,(\%)\end{array}$ & OR(95\%CI) & $\mathrm{p}$-value \\
\hline \multicolumn{5}{|l|}{ Age at menarche } \\
\hline 13 years and less & $33(37.9)$ & $54(62.1)$ & $1.47(0.66-3.28)$ & 0.338 \\
\hline More than 13 years & $12(29.3)$ & $29(70.7)$ & 1.00 & \\
\hline \multicolumn{5}{|l|}{ Interval of menstrual cycle } \\
\hline$<28$ days & $6(27.3)$ & $16(72.7)$ & $0.71(0.24-2.10)$ & 0.540 \\
\hline 28 days & 19(39.6) & $29(60.4)$ & $1.24(0.56-2.74)$ & 0.588 \\
\hline$>28$ days & $20(34.5)$ & $38(65.5)$ & 1.00 & \\
\hline \multicolumn{5}{|l|}{ Duration of bleeding } \\
\hline More than 4 days & $32(36.8)$ & $55(63.2)$ & $0.79(0.36-1.75)$ & 0.575 \\
\hline 4 days and less & $13(31.7)$ & $28(68.3)$ & 1.00 & \\
\hline \multicolumn{5}{|l|}{ Pattern of Menstrual cycle } \\
\hline Irregular & $13(41.9)$ & $18(58.1)$ & $1.46(0.64-3.36)$ & 0.364 \\
\hline Regular & $32(33.0)$ & $65(67.0)$ & 1.00 & \\
\hline \multicolumn{5}{|l|}{ Abdominal pain started at menarche (Year) } \\
\hline With start of Menarche & 21(33.3) & $42(66.7)$ & $0.85(0.41-1.76)$ & 0.671 \\
\hline Before or after start of menarche & $24(36.9)$ & $41(63.1)$ & 1.00 & \\
\hline \multicolumn{5}{|l|}{$\begin{array}{l}\text { Abdominal Pain Started at the time of menstrual } \\
\text { bleeding (day) }\end{array}$} \\
\hline On the same day of start of menstrual bleeding & $19(30.2)$ & $44(69.8)$ & $0.64(0.31-1.34)$ & 0.244 \\
\hline $\begin{array}{l}\text { Before and after one day of start of menstrual } \\
\text { bleeding }\end{array}$ & $26(40.0)$ & $39(60.0)$ & 1.00 & \\
\hline \multicolumn{5}{|l|}{ Duration of pain during menstrual bleeding } \\
\hline Less than 1day & $20(31.3)$ & $44(68.8)$ & $0.70(0.34-1.47)$ & 0.355 \\
\hline \multicolumn{5}{|l|}{ Family history of pain during menstrual bleeding } \\
\hline Yes & $20(30.8)$ & $45(69.2)$ & $0.67(0.32-1.40)$ & 0.291 \\
\hline No & $25(39.7)$ & $38(60.3)$ & 1.00 & \\
\hline \multicolumn{5}{|l|}{ Severity of pain } \\
\hline Severe & $22(61.1)$ & $14(38.9)$ & $\begin{array}{l}4.84(1.90- \\
12.33)\end{array}$ & 0.001 \\
\hline Moderate & $11(25.6)$ & $32(74.4)$ & $1.06(0.41-2.72)$ & 0.904 \\
\hline Mild & $12(24.5)$ & $37(75.5)$ & 1.00 & \\
\hline
\end{tabular}

Table 6| Multivariable analysis of factors associated with self-medication practice during pain in menstrual bleeding among study subjects

\begin{tabular}{|c|c|c|c|}
\hline Characteristics & aOR & $(95 \% \mathrm{CI})$ & p-value \\
\hline \multicolumn{4}{|l|}{ Marital Status } \\
\hline Married & 3.51 & $1.13-10.87$ & 0.029 \\
\hline Unmarried & 1.00 & 1.00 & \\
\hline \multicolumn{4}{|l|}{ Severity of pain } \\
\hline Severe & 4.82 & $1.77-13.10$ & 0.002 \\
\hline Moderate & 4.77 & $1.79-12.67$ & 0.002 \\
\hline Mild & 1.00 & 1.00 & - \\
\hline
\end{tabular}




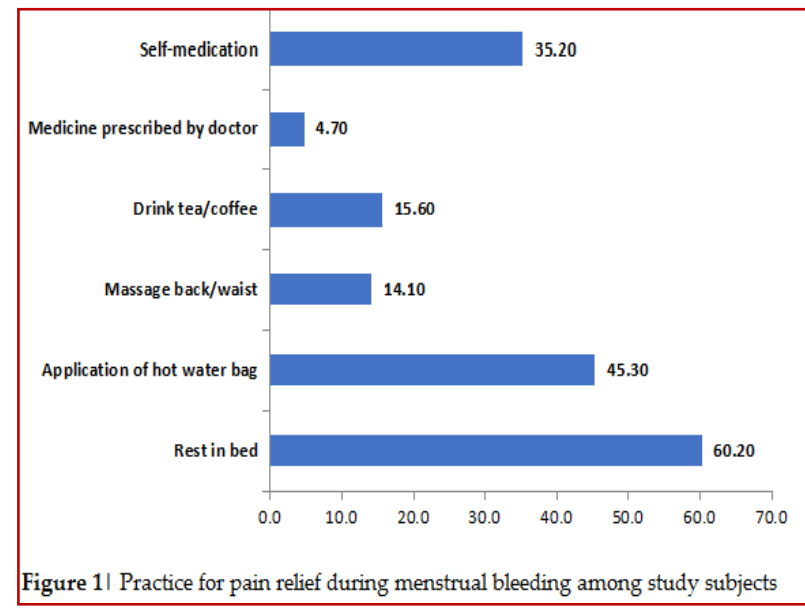

Self-medication practice for relief of pain during menstrual bleeding was observed in $35.20 \%$ of students, and only $4.70 \%$ took medicines prescribed by doctor whereas the remaining
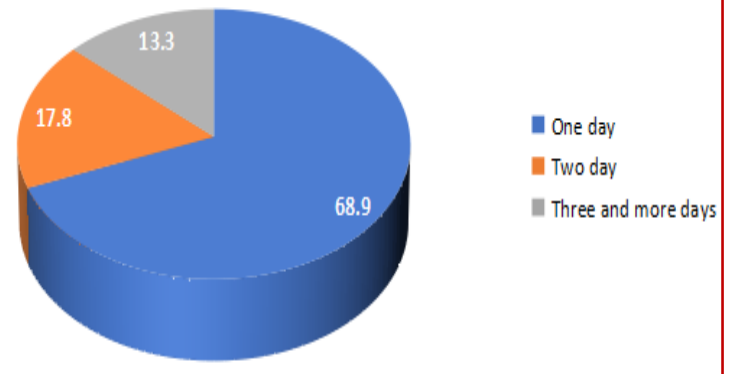

Figure 3 । Duration of self-medication

The most commonly self-medicated drug was mefenamic acid $(64.4 \%)$, followed by paracetamol $(40 \%)$, Ibuprofen $(26.7 \%)$ and nimesulide $(13.3 \%)$, (Figure 2).The duration of self-medication was 1 day for $68.9 \%$ of the students, 2 days for $17.8 \%$ of

\section{DISCUSSION}

Self-medication practice has been practiced by literate as well as illiterate people due to easy availability of drugs and lack of strict regulatory authority, which has lead to issues like development of antimicrobial resistance, tolerance and/or dependence and many more undesired effects. In this study, nursing students were enrolled for determining the prevalence as well as

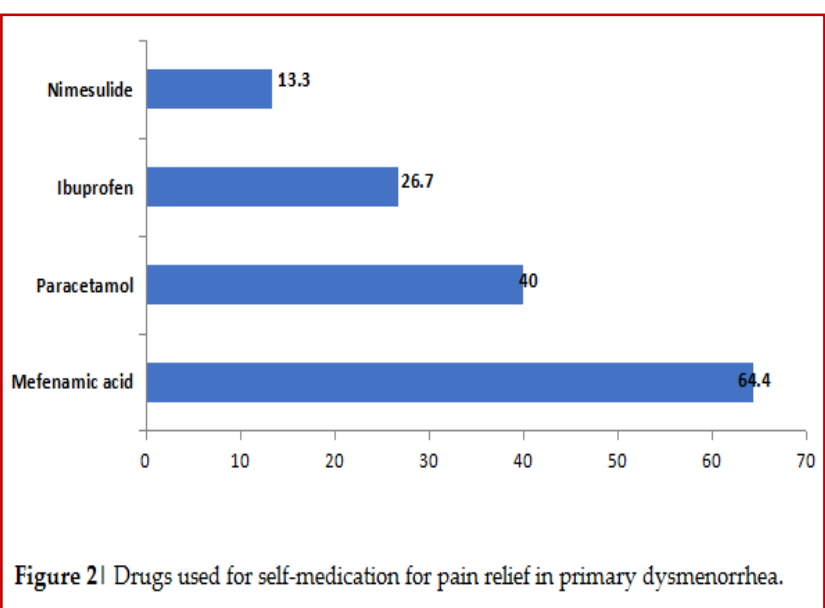

students practiced non-pharmacological measures like, resting in bed $(60.20 \%)$, application of hot water bag $(45.30 \%)$, massaging back/waist $(14.10 \%)$ and drinking tea/coffee $(15.60 \%)$, as shown in $\quad$ Figure 1.

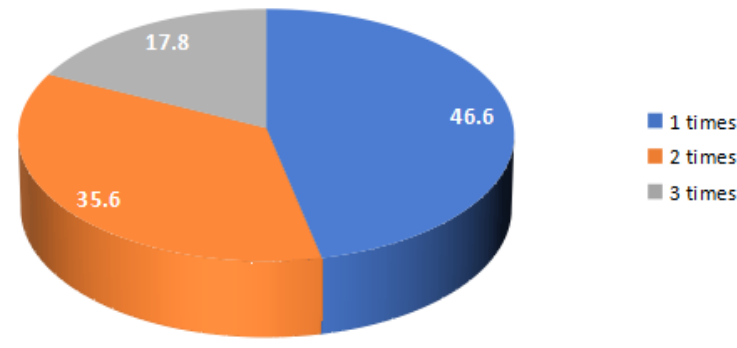

Figure 4 I Frequency of drug intake per day

students and 3 days for $13.3 \%$ of students (Figure 3).The pain associated with menstrual bleeding was relieved by intake of a drug only once a day in $46.6 \%$ of students, while the pain was relieved by intake of a drug 3 times per day in $17.8 \%$ of students

(Figure

$4)$.

pattern of SM in primary dysmenorrhea. In this study, the mean age of female students was $18.92 \pm$ 2.52 which was consistent to the mean age of $19.12 \pm$ 0.87 years and 16.7 years in study conducted by Jayanthi B. et al. [13] and Chiou M-H et al. [14] respectively. $82.7 \%$ of students were unmarried and $17.3 \%$ were married. The higher percentage of unmarried students suggests that, most of their 
families had sound knowledge about the consequences of childhood marriage. Majority of the students belonged to intermediate level (65.4\%) compared to bachelor level (34.6\%). Also, majority students were residents of province 2 as the study was carried out in province 2, Nepal.

The mean age of menarche was $13.20 \pm 1.53$ years, mean interval of menstrual cycle was $30.29 \pm 7.26$, the duration of menstrual bleeding was $4.84 \pm 1.15$ and regular menstrual bleeding pattern was seen in $77.6 \%$ of the females which were comparable with the findings of Parra-Fernández ML et al. [15], where the average age of menarche was $12.15 \pm$ 1.52; the majority of the women reported having a regular menstrual cycle $(72.8 \%)$, with average cycles of $29.05 \pm 4.46$ days, and a menstrual period lasting for $5.02 \pm 1.26$ days, and Chiou M-H et al. [14], where the average age of menarche was between the ages of 12 to $14,83.9 \%$ had menstruation periods that lasted between 4 to 6 days. However, $61.6 \%$ of them didn't have regular menstruation. Similarly, the mean age at menarche was $12.6 \pm 1.6$ years in study done by Sugumar R et al. [16], which is in consistence with our study.

This study showed that, most of the female students had a regular pattern (77.6\%) of menstrual bleeding similar to study done by WO Adebimpe et al. [17]. $82.1 \%$ of the female students reported lower abdominal pain during menstrual bleeding, of which $48.4 \%$ had pain pain for less than 1 day, $47.7 \%$ had pain for $1-3$ days and $3.9 \%$ had pain for more than 3 days. $28.1 \%$ of the respondents had severe, $33.6 \%$ had moderate and $38.3 \%$ had mild lower abdominal pain, which is in contradiction with study done by Parra-Fernández ML et al. [15], where $6.3 \%$ perceived mild pain, $26.3 \%$ moderate pain and $67.4 \%$ perceived intense pain. Prevalence of SM practice was found to be higher in students aged $>20$ years $(40 \%)$ which is comparable to the results of study conducted by Jayanthi B. et al. [13]. Also, SM practice in upper caste group was $39.2 \%$, in married students $61.1 \%$ and in bachelor level students $37.5 \%$.

In our study, SM practice, with age at menarche $\leq$ 13years $(37.9 \%)$, with 28 days menstrual cycle interval (39.6\%), with more than 4 days of bleeding duration $(36.8 \%)$ and with irregular menstrual bleeding $(41.9 \%)$ were associated with higher pattern of SM. Similarly, SMP practice was associated with history of abdominal pain before or after start of menarche $(36.9 \%)$, with abdominal pain starting before and after one day of start of menstrual bleeding (40\%), with pain for $\geq 1$ day $(39.1 \%)$ and with severe pain during menstrual bleeding $(61.1 \%)$. These findings are similar to results obtained by Pavyde E. et al. [18], where the presence of dysmenorrhea was associated with younger age $(90.4 \%)$, no previous pregnancy $(91.7 \%)$, irregular menstrual cycle $(\mathrm{OR}=2.270)$, younger age at menarche(for $\leq 12$ years, $\mathrm{OR}=2.361$ ), longer menstrual bleeding duration $(\geq 6$ days, $\mathrm{OR}=$ 3.141) and presence of premenstrual syndrome $(\mathrm{OR}=3.189)$ were reported.

Based on multivariable analysis, SMP was associated more with married students and with severe lower abdominal pain during menstrual bleeding in this study. SMP for relief of pain during menstrual bleeding was observed in $35.20 \%$ of female students, on the contrary it was $76 \%$ and $66.7 \%$ in study done by Gama ASM et al. [19], and Pavydè E. et al. [18] respectively.

Only $4.70 \%$ of the students took medicines prescribed by doctor similar to the findings of study done by Sugumar $\mathrm{R}$ et al. [16], whereas the remaining students practiced non-pharmacological measures like, resting in bed $(60.20 \%)$, application of hot water bag $(45.30 \%)$, massaging back/waist $(14.10 \%)$ and drinking tea/coffee $(15.60 \%)$ which are lower than the findings of Parra-Fernández ML et al. [15], where $43.8 \%$ of women with primary dysmenorrhea claimed to use non-pharmaceutical methods to alleviate pain, the most common being: antalgic position $(23.2 \%)$, massages $(21.9 \%)$, local heat $(17.9 \%)$ and relaxation $(16.1 \%)$. Also, the results of our study on the effectiveness of nonpharmaceutical methods was similar to the findings of a systematic review published in 2019 by Armour et al. [20]. However, due to the lack of proper education on self-care methods in dysmenorrhea, there is no coherence between self-care methods with proven effectiveness and the frequency of their use by the majority of the participants in this study.

Dysmenorrhea being present early on and particularly in the initial days is due to the increased release of prostaglandins (PGs) causing intense uterine contractions, decrease uterine blood flow causing ischemic necrosis of endometrial lining and nerve hypersensitivity, ultimately causing expulsion of the endometrial lining. Nonsteroidal anti-inflammatory drugs (NSAID's) which act by inhibiting PGs synthesis reduces menstrual 
blood flow hence reducing the dysmenorrhea associated pain and discomfort. Pharmacological agents used commonly were analgesics such as paracetamol, ibuprofen, mefenamic acid, dicyclomine, nimesulide and diclofenac. Use of NSAIDs for SM in our study is comparable with study done by Fatima A et al. [21] and ParraFernández ML et al. [15]. The most commonly self medicated drugs were NSAID group of drugs, namely Mefenamic acid (64.4\%), followed by paracetamol (40\%), Ibuprofen (26.7\%) and Nimesulide $(13.3 \%)$, these findings were in accordance with the study done by Jayanthi B. et al. [13], and Gama ASM et al. [19]. However, in a study done by Rashidi et al. [22], ibuprofen (37.1\%) was the most frequently self- prescribed medications for dysmenorrhea, whereas mefenamic acid plus

\section{CONCLUSION}

The present study demonstrates that, selfmedication of drugs is lower in primary dysmenorrhea, probably due to lack of knowledge of drugs among nursing students for pain relief in primary dysmenorrhea. NSAID's namely, mefenamic acid and paracetamol followed by ibuprofen are the most self medicated drugs for pain control in dysmenorrhea. However, self-medication is an important issue dicyclomine combination was effective and most commonly used self-medication in study done by Mahadevan $S$ et al. [23]. In the present study, the duration of SM was 1 day for $68.9 \%$ of the students, 2 days for $17.8 \%$ of students and 3 days for $13.3 \%$ of students. The pain associated with menstrual bleeding was relieved by intake of a drug only once a day in $46.6 \%$ of students, while the pain was relieved by intake of a drug 3 times per day in $17.8 \%$ of students, similar results were also reported in study done by Pavydè E et al. [18], and ParraFernández ML et al. [5]. The average consumption was $3.62 \pm 2.74$ pills per menstruation. [15]. The consumption of NSAIDs was most frequent among students experiencing severe pain, compared to those experiencing moderate or mild pain.

which needs to be properly and timely addressed through education programs on the drawbacks of self-medication of drugs and counselling them for consumption of only prescribed drugs for pain relief in primary dysmenorrhea along with other home remedies.

Self-medication of drugs was found to be lower in primary dysmenorrhea, probably due to lack of knowledge of drugs among nursing students.

\section{ADDITIONAL INFORMATION AND DECLARATIONS}

Acknowledgements: The authors would like to thank nursing department of JMC for logistic support and all individuals who rendered help and participated during the study period.

Funding: Self

Competing Interests: The authors declare no competing interests.

\section{REFERENCES}

1. WHO (2000) Guidelines for the Regulatory Assessment of Medicinal Products for Use in Self-Medication., Geneva. 2013.

2. World Health Organization. Role of Pharmacists in Self-Care and SelfMedication.the Fourth Consultative Group Meetings on the Role of the Pharmacist in the Health Care System Organized by WHO in Collaboration with the International Pharmaceutical Federation. The
Hague, The Netherlands: World Health Organization. 1998.

3. De Sanctis V, Soliman AT, Daar S, Di Maio S, Elalaily R, Fiscina B, Kattamis C. Prevalence, attitude and practice of self-medication among adolescents and the paradigm of dysmenorrhea self-care management in different countries. Acta Biomed. 2020;91(1):182-9.

4. James H, Handu SS, Al Khaja KA, Otoom S, Sequeira RP. Evaluation of the knowledge, attitude and practice of self-medication among first-year medical students. Med PrincPract. 2006;15:270-75.

5. Pan H, Cui B, Zhang D, Farrar J, Law F, et al. Prior Knowledge, Older Age, and Higher Allowance Are Risk Factors for Self-Medication with Antibiotics among University Students in Southern China. PLoS ONE. 2012;27:e41314. 
6. Klemenc-Ketis Z, Kersnik J. Sources and predictors of home-kept prescription drugs. Int $\mathrm{J}$ Clin Pharmacol Ther. 2010;48:705-7.

7. Coco AS. Primary dysmenorrhea. Am Fam Physician. 1999;60(2):489-96.

8. Agarwal AK, Agarwal A. A study of dysmenorrhea during menstruation in adolescent girls. Indian J Community Med. 2010;35:159-64.

9. Nicholls PJ, Stevens RG, Albahsain NA. Medication used by Saudi girls. Saudi Pharm J. 2002;10:126-132.15.

10. MHW, Chung JTN, Munro JGC. Self medication among secondary school pupils in Hong Kong: A descrip-tive study. Fam Pract. 1989;6:303-306.

11. Hebeeb GE, Gearhart JG. Common patient symptoms: patterns of selftreatment and prevention. J Miss State Med Assoc. 1993;34:179-181.

12. Shankar P, Partha P, Shenoy N. Selfmedication and non-doctor prescription practices in Pokhara valley, Western Nepal: a questionnaire-based study. BMC Fam Pract. 2002;3(1):17.

13. Jayanthi B, Anuradha HV. Comparison of self-medication practice for dysmenorrhoea in medical, nursing and dental students. International Journal of Basic \& Clinical Pharmacology. 2016;S.1:5(2):269-73.
14. Chiou M-H, Wang H-H. Predictors of dysmenorrhea and self-care behavior among vocational nursing school female students. J Nurs Res. 2008;16:17-25.

15. Parra-Fernández ML, Onieva-Zafra MD, Abreu-Sánchez A, RamosPichardo JD, Iglesias-López MT, Fernández-Martínez E. Management of Primary Dysmenorrhea among University Students in the South of Spain and Family Influence. Int J Environ Res Public Health. 2020;17(15):5570.

16. Sugumar $R$, Krishnaiah $V$, Channaveera GS, Mruthyunjaya S. Comparison of the pattern, efficacy, and tolerability of self-medicated drugs in primary dysmenorrhea: a questionnaire based survey. Indian J Pharmacol. 2013;45(2):180-183.

17. Adebimpe WO, Farinloye EO, Adeleke NA. Menstrual pattern and disorders and impact on quality of life among university students in South-Western Nigeria Journal of Basic and Clinical Reproductive Sciences. 2016;5(1):27-32.

18. Pavydè E, Šilgalienè $M$, Paulionytė M, Nadisauskiene RJ, Stankevicius E, Sveikata A. Primary dysmenorrhea: prevalence, risk factors and selfmedication. 2014.
19. Gama ASM, Secoli SR. Selfmedication among nursing students in the state of Amazonas - Brazil. Rev Gaucha Enferm. 2017; 18;38(1):e65111.

20. Armour M, Smith CA, Steel KA, MacMillan F. The effectiveness of self-care and lifestyle interventions in primary dysmenorrhea: A systematic review and meta-analysis. BMC Complement. Altern. Med. 2019;19(1):22.

21. Fatima A, Mamatha KR, Ambika B, Rajarathna K. Self-medication practice in primary dysmenorrhea among medical and paramedical students - A cross-sectional questionnaire study. Natl J Physiol Pharm Pharmacol. 2017; 7(5):458463.

22. Al-Rashidi A, Al-Subaie SA, Farooqui M. Self-medication practice in primary dysmenorrhea among medical and pharmacy students in Unaizah-KSA- A cross sectional Questionnaire study. ISPOR. 2018;21:S(3):S220.

23. Mahadevan $S$, Dharman $D$, Manohar D, Daran SS, Vinod VA, Roy A. The self-medication practice in primary dysmenorrhea among pharmacy students-a cross-sectional questionnaire study. Int J Res Pharm Hos \& Clin. Pharm. 2019;1(4):97-100. 